\section{THE VACCINATION ACTS.}

By John C. McVaIr, M.D.

(Continued from p. 145.)

The Authoritims for Local administration of the VACCINATION ACTS.

TnIs is the last question with which I propose to deal. For its complete consideration there would be necessary a knowledge of administrative detail which only the Local Government Board's staff can be expected to possess. Regarding the unsuitability of Boards of Guardians as vaccination authorities there is a very general consensus of opinion. They are entirely Poor-law authorities, and the very idea of pauperism should be dissociated from the provision made for public vaccination. Also, guardians have no other public health functions, and vaccination is quite outside the natural field of their duties.

At least three bodies have been suggested as best suited for administration of the Acts : the Local Government Board, the local sanitary authorities, and the county councils. In commenting on these suggestions it is to be understood that I am expressing merely my own individual npinion and not that of any society or committee of which I have the honour to be a member.

\section{The Local Government Board and Vaccination} Prosecutrons.

The Local Government Board does not seem to me to be at all a suitable-body for the bulk of the work. The whole tendency of administration in this country is in the direction of devolution or localization, not of centralization. I cannot think either that Parliament would regard the Board as the body best fitted to carry out all the details of local administration of the Vaccination Acts, or that the Board itself would wish to undertake the duties.

There is, however, one part of the work which ought to be undertaken by the Board. Legal proceedings for prosecution of defaulters should be a duty, not of any local authority, nor of any officer appointed by a local authority, but of a public prosecutor appointed directly by the Board and responsible directly to it. At present vaccination officers are charged with these duties, and there is frequent friction, and complaint by guardians that in this matter they have not the control of their own servants, appointed and paid by themselves. All such complaints tell more or less against the whole vaccination system, and no such opportunities for criticism slould be afforded to opponents Still worse would it be to place the responsibility directly on the local authorities themselves. That was the system until within the last few years, when the law officers of the Grown decided that, according to the Acts, the vaccination officer must in this matter proceed independently of his local authority. To revert to the former practice by alteration of the law would be to encourage ad hoc elections, with all their known evils. The question would be, not the general fitness of a candidate for membership of the local body, but what his views might be on vaccination and the legal obliigation thereto. Whatever local authority therefore be selected for the general administration of the law should he protected from deterioration by not being burdened with the function under discussion; and for the reasons already given no officer appointed and paid by the local authority should be similarly handicapped. If in every district the Local Government Board were to appoint a law agent for this purpose, the duty of the vaccination officer as concerns prosecutions would be strictly limited to handing to the agent periodical lists of defaulters.

There might, it seems to me, be other benefits attending such a system. I have already held that the purpose of prosecutions should be not to punish antivaccination folly, but to promote the practice of vaccination, and that if any method could be devised by which the merely indifferent and neglectful parent could be distinguished from the irreclaimable antivaccinationist, no good purpose would be served in penalizing the latter by Act of Parliament in addition to the penalties he has to suffer at the hands of small-pox. I observe that quite lately in Leicester two small-pox deaths and one non-fatal attack occurred among persons who would not be persuaded to be vaccinated even under exposure to infection. Now in Scotland there is in every district a functionary called a procurator-fiscal-a local lawyer selected and paid by the Crown to conduct inquiries and prosecutions on its behalf. His duties include reporting to the Crown authorities on cases as to which the question of prosecution is doubtful. He has nothing to do with the prosecution of vaccination defaulters, and I bring him in here only to indicate how such a system might be introduced in England owith regard to these defaulters. If a local law agent were entrusted in each district in England with such work, he might often be able, through inquiry as to individual cases; to furnish such information to the Local Government Board (with whom the decision would rest), as might prevent prosecutions which could have no effect in promoting vaccimation. Such a system would be entirely in accordance with the purpose which led the Royal Commission to recommend a Con. science Clause-the purpose being the promotion of the practice of vaccination.

The Local Authority.

Assuming now that the Local Government Board will not undertake general local administration of the proposed Vaccination Act, but will at the same time relieve local authorities of the work of prosecution, the question remains, Which is the best local body to entrust with routine administration - the employment of public vaccinators and vaccination officers, and the carrying on of systematic vaccination and revaccination?

In discussing this question in the Vaccination Number of the British Medical Journal in July, 1902, I pointed out that vaccination is essentially a public health measure, and ought to be entrusted to the local authority charged with other public health measures," including hospital accommodation and disinfection. That principle remaing true, but since July I have seen reason to suggest a modification of its application. For good local administration experience shows that a sufficiently large area is very important, while in the rural districts of England, the population controlled by individual authorities is often very small, probably too small for the best interests of the localities concerned, in the matter of combined efficiency and economy. In Scotland, since 1889 , the area of rural sanitary administration has been the county district, and the smaller counties form only a single district. Great benefits have resulted from this system as compared with the former administration of each small parish separately. For rural districts in England I venture to suggest that the county council would be the best vaccination authority. Counties being large, the councils ought to have such powers of devolution or allocation of work as would make for efficiency. At present these bodies have not many udministrative duties, and they would of course have to be given the power of appointing the necessary officers and carrying on all work devolved on them. County boroughs are already sanitary authorities, and have sufficient areas for good administration. In Londen the same remark applies to the borough councils.

These bodies would in nearly all cases be large enough to make possible the employment of whole-time public vaccinators and vaccination officers. In this as in everything else, to get the best class of men proper salaries would have to be offered, but even with good salaries I think the system would be very economical as compared with the present method of payment by fees of public vaccinators who are also engaged in medical practice. Exceptions of course might have to be made in some places in view of already existing arrangements, and I am merely stating a general principle. The appointment of whole-time officials would not interfere with the rights of the public to go to their own medical attendants, or with the rights of practitioners to vaccinate their own patients. I have already suggested payment for certificates by private practitioners where the operation had been successful according to a standard required under the suggested Vaccination Act by the Local Government Board. The machinery of county council and large borough administration should make it possible to give some heed to verification of certificates where any suspicion of falsity might exist, and I have already said that false certification should be a severely punishable offence. The areas of work for whole-time public vaccinators should be sufficiently large to ensure their full employment even allowing for a considerable percentage of vaccinations by private practitioners, and to begin with it might be proper to make the districts of public vaccinators too large rather than too small, as it would be easier to add to the number of officials than to diminish it.

In addition to all this, there should be full power to every sanitary authority, however small, to carry out vaccination and revaccination in times of emergency-as in presence of 
small-pox. This power was definitely conferred on all sanitary authorities in Scotland by the Public Health Act of 1897 , and has been found very valuable. The expenses of administering the Acts in County Councils and large boroughs should be charged by rate over the whole area. All expenses connected with outbreaks of small-pox should be charged by rate within the sanitary areas affected, even where these are small, as in rural districts. Small-pox outbreaks, under a Vaccination and Revaccination Act with an exemption clause, would depend largely on the amount of exemption, and localities which had extensively resorted to the Conscience Clause should pay for their own small-pox, in the same way as would well vaccinated and revaccinated localities.

Such are the general lines on which it appears to me that a new Vaccination Act might be framed. The objects which I have kept before me are, not the punishment by law of the incorrigibly wrong-headed antivaccinationist, but the protection of the country against small-pox by the promotion of systematic vaccination and revaccination to the greatest degree compatible with the admission of duly restricted exemption certificates, the purity of lymph supply, and an administrative system fitted to achieve these purposes effectively, and at the same time economically, without reasonably avoidable interference "with existing interests.

\section{THE PREVENTION OF CONSUMPTION.}

\section{Great Britain.}

The National Association.

A meeting of the Council of the National Association for the Prevention of Consumption was held on January 12th; Sir William Broadbent in the chair.

The Spitting Nuisancc.-The attention of the Council having been called to the fact that, notwithstanding the numerous notices against spitting which have been placed in various railway carriages, tramcars, and places of public resort, this disagreeable and dangerous habit still continues; and also in view of the fact that spitting on the cars of certain tramway companies and in covered places of public resort in the county of Glamorgan has already been made a penal offence, it was decided that some further action was called for. The following resolution was therefore proposed by Mr. Malcolm Morris, seconded by Dr. Lionel Weatherly, supported by Dr. Arthur Ransome, and carried unanimously:

That spitting on the floors of public buildings, on platforms, corridors, staircases, and public carriages or passenger boats, or in any covered place of public resort, should be forbidden by law.

Tuberculosis in Lunatie Asylums.-The Council at the same meeting also resolved :

That the Council of the National Association for the Prevention of Consumption, having read the report of the Tuberculosis Committee of the Medico-Psychological Association of Great Britain, are of opinion that the suggestions therein expressed are most valuable, and they urge the Commissioners in Lunacy to do their utmost to get the committees of the county and borough asylums to carry these suggestions into effect.

Ventilation of Factories and Workshops.-The attention of the Council has also been called to the report of a Departmental Committee (Dr. John Haldane and Mr. E. H. Osborn) on the Ventilation of Factories and Workshops, 1902 (Blue Book, Cd. 1302). The chief recommendation in the report is (page 5) that "such a standard of ventilation should be prescribed for all classes of factories and workshops not otherwise dealt with; the proportion of carbonic acid in the air at about the breathing level, and away from the immediate influence of any special source of contamination............ shall not.......... rise during daylight, or after dark when only electric light is used, beyond 12 volumes of carbonic acid per Io, 000 of air, and that when gas or oil is used for lighting the proportion shall not exceed 20 volumes after dark, or before the first hour of daylight." The Council understands that, in accordance with the views of a previous Committee, an Act was passed in 1897 fixing the standard of 9 volumes of carbonic acid in all humidified cotton cloth factories, and that this Act had been very successful in improving the condition of the workers in these factories. The Council therefore beg to express their opinion that the newly-suggested standard of ventilation should not be adopted by the Government, as it would probably prove detrimental to the public health, and would tend to increase the prevalence of tuberculous disease.

The Local Government Board and Notification. - The Willesden District Council at its meeting on January $13^{\text {th }}$ had under consideration a letter from the Local Government.
Board, dated December Ist, 1902, stating that the Board had not in any case sanctioned the inclusion of phthisis among the diseases compulsc rily notifiable in a district. In the Board's view phthisis is not a disease to which the principle of compulsory notification could with advantage be applied, and it is pointed out that many persons who would be notified as suffering from phthisis would be individuals in whom the disease is so little advanced that not a few of them may be expected to have many years of life in prospect, during which it will be imperative on them to gain a livelihood for them. selves and also for their families. Many authorities have entered into an arrangement with the local medical practitioners for the voluntary notification to the medical officer of health of cases of pulmonary tuberculosis occurring in their respective practices, and it is intimated that the district council had power to do this without the Board's consent, and to pay a reasonable fee for each notification. It is stated that the Board is not aware that any local authorities have obtained powers in local Acts to require notification to themselves or their medical officers of health of cases of phthisis occurring in their districts. The Board understands, however, that applications have been made to the Secretary of state for the Home Department in certain cases to confirm bylaws made by county councils dealing with the practice of expectorating in public places. The Board is advised that it is within the power of a district council under the Public Health Act, 1875, to provide hospital accommodation for persons suffering from phthisis.

Cambridge.-The Medical Officer of Health, Dr. J. H. C. Dalton, presented a report which was adopted by the guardians on December 3 rd, 1902, in which he gives the results of his inquiries into the prevalence of consumption in the borough. Not only is the amount of consumption in the borough smaller than in many other districts, but it has markedly decreased of late. Nearly all the cases which have come before the Board are incurable cases which have already been under treatment in the Addenbrooke's Hospital or elsewhere, and the majority are at present in the hospital. There is evidence to show that many of the cases are the result of infection from other members of the family living in the same house. The problem in Cambridge is, therefore, not so much the provision of sanatoria for consumptives as of means to prevent the spread of the disease from one member of a family to others. Dr. Dalton accordingly suggests that a leaflet, the text of which he submitted, be printed for distribution to patients by the relieving officers, and that visits be occasionally made to ascertain that the proper precautions are carried out. He further recommends that the sanitary authority be informed of any fresh cases and of deaths from phthisis with a view to the cleansing and disinfection of rooms. He suggests that consumptive patients in the workhouse be isolated as far as possible, and that the spitting regulations referred to in the leaflet be observed by these patients.

Glasgow.-The members of the Council of the Glasgow branch of the National Association for the Prevention of Consumption and Other Forms of Tuberculosis have purchased the estate of Bellefield, near Lanark, as well suited for the establishment of a sanatorium for the treatment of consumptives. The estate is some $500 \mathrm{ft}$. to $700 \mathrm{ft}$. above realevel, on a gravel soil, and well sheltered from the north and east winds. It is estimated that about $£ 85.000$ will be required to establish the sanatorium satisfactcrily, and subscriptions are solicited for the purpose. The mansion house will furnish quarters for the resident staff, and it is proposed that for the present accommodation should be provided for males only.

Dundee.-Ex-Provost Moncur is determined that the Dundee Sanatorium, which already owes so much to him, shall not be stinted for funds. The cost of the sanatorium at Sidlaws has been found to exceed considerably the original 4 stimate. It will be remembered that the site was given by the late Earl of Airlie, and that a sum of $f 10,000$ was given by ex-Provost Moncur towards building the sanatorium. This being insufficient for the purpose, the gift was increased to $£_{1} 5,000$, and now this is said not to be sufficient. Ex-Provost Moncur has, however, generously assured the Committee that they need have no anxiety as to the cost, and it is authoritatively stated that before the institution is ready for the reception of patients ex-Provost Moncur will have spent over $£ 20,000$ on its erection and equipment.

The net value of the estate of the late Mr. Manley Sims is estimated at $£ 35,000$. 